\title{
Logistic Methods in Calculating Mortality Index in Hidalgo México
}

\author{
Gerardo Martínez-Guzmán, Mario Mauricio Bustillo-Díaz, Alejandro Rangel-Huerta, \\ Gabriel Juárez-Díaz, Apolonio Ata-Pérez, Nicolás Quiroz-Hernández, \\ Rogelio González-Velázquez, María Beatríz Bernabe-Loranca
}

Facultad de Ciencias de la Computación, Benemérita Universidad Autónoma de Puebla, Puebla, México Email: j.gabriel@rocketmail.com

Received 3 June 2015; accepted 5 July 2015; published 8 July 2015

Copyright (C) 2015 by authors and Scientific Research Publishing Inc.

This work is licensed under the Creative Commons Attribution International License (CC BY). http://creativecommons.org/licenses/by/4.0/ c) (7) Open Access

\begin{abstract}
Mortality projections in a population are based on the prior analysis of mortality in a region, however, there are populations where data are not available or not reflect its real mortality level, that is, the projections depend on hypothesis strength of previous data. Based on these assumptions, the mathematical method Genova I Maleras 1997 used the most recent data and the model tables from the United Nations (UN). This method was applied to a mortality survey of the population of Hidalgo State, Mexico, projecting to year 2030. This method has not been applied in Mexico.
\end{abstract}

\section{Keywords}

Mortality Projection, Genova I Maleras Method

\section{Introduction}

The surveys and measurements of mortality act as indicators of socieconomic and health progress [1] showing the evolution and trends for sectors of main universal humanity concern: health, life extension and the possibility of avoiding the premature death allow to detect differences between social groups or geographic areas and population groups by age and gender, in order to identify the progress or setback degree towards better welfare conditions, to help identify target groups or regions for health programs or evaluate the success of already instituted programs.

There are several methodologies for the calculation of Life tables [2], based mainly on previous population data. However, data from previous censuses are not reliable, and the amount of data is limited. The mathematical model of Genova I Maleras 1997 [3], can be used considering only the latest and most reliable data and tables developed by the UN [4]. This method is applied for the first time in Mexico, and focused in the region of 
Hidalgo State, in order to study the behavior of mortality and make a projection until year 2030.

\subsection{Model Life Tables from United Nations}

Two family sets of standard model life tables (Coale-Demeny 1966, 1989 and United Nations, 1982) are used commonly in order to obtain a variety of mortality indicators [3]. However, these two model life table sets, where designed mainly to be used in developing countries, covering the mortality patters for a maximum life expectancy of 75 years. Thomas Buettner in 1998 extends the sets of model life tables with a life expectancy from 75 to 92.5 years.

With the enlargement of the projection horizon for all countries up to 2100, as part of the review in 2010 by the World Population Perspectives from the UN, a new set of extended model life tables was necessary, such that were designed in 2010 by the staff from the Population Division of the United Nations (Nan Li and Patrick Gerland), based on the Lee-Carter modified approach. The model life tables reach a life expectancy up to 100 years, these can provide a wide margin for mortality projection, even for populations that have a high life expectancy. These model life tables are used in order to calculate the mortality projection in this work.

\subsection{Features of the Mortality Table}

Diverse features contained in a mortality table, its meaning and calculation formula of each one are described as follows:

${ }_{n} m_{x}$ : Specific mortality rate by age.

${ }_{n} q_{x}$ : Death probability.

$l_{x}$ : Survivors at precise age.

${ }_{n} L_{x}$ : Stationary population of the table.

${ }_{n} Z_{x}$ : Passing perspective probability.

where:

$x$ : precise age at the beginning of age range.

$n$ : age range width.

1) Specific mortality rate by age $\left({ }_{n} m_{x}\right)$.

Is calculated from the number of deaths occurred in the population within the group at specific ages between $x$ and $x+n$, and the person-years lived by the population in that age group.

$$
{ }_{n} m_{x}=\frac{{ }_{n} D_{x}}{{ }_{n} P_{x}}
$$

2) Death probability $\left({ }_{n} q_{x}\right)$

Represents the probability that a person at specific age $x$, in case of death before to reach the age $x+n$. With this feature the mortality pattern for the population is established.

$$
{ }_{n} q_{x}=\frac{2 * n *{ }_{n} m_{x}}{2+\left(n *{ }_{n} m_{x}\right)}
$$

It is known as actuarial method because assumes a linear distribution of the events within the age range.

3) Survivors $\left(l_{x}\right)$

This feature allows to calculate the evolution of a generation under a mortality estimation process. The initial population of the generation is generally a power of ten, and is called the root of the table, in this case $l_{0}=10000$.

$$
l_{x+n}=l_{x} *\left(1-{ }_{n} q_{x}\right)
$$

Obtaining as result the sub-population surviving at an exact age.

4) Stationary population $\left({ }_{n} L_{x}\right)$

Represents the total time lived within a range of age in a population with the mortality characteristics reflecting from the table.

5) Passing perspective probability $\left({ }_{n} z_{x}\right)$

$$
{ }_{n} L_{x}=n *\left[0.5 *\left(l_{x}+l_{x+n}\right)\right]
$$


This probability is estimated between age ranges, by taking the stationary population from the table.

$$
{ }_{n} Z_{x}=\frac{{ }_{n} L_{x+n}}{{ }_{n} L_{x}}
$$

In order to calculate the perspective probability from birth until the first five-year age group is calculated as follows:

$$
Z_{0}=\frac{L_{0}+{ }_{4} L_{1}}{5 * l_{0}}{ }_{4} Z_{1}=\frac{{ }_{5} L_{5}}{L_{0}+{ }_{4} L_{1}} .
$$

\section{Mathematical Model}

The Genova I Maleras model [4] is applied in order to obtain the projection from the mortality tables until the horizon year 2030 for the Hidalgo state population. In this work is used to obtain the mortality projection for women and men applied in a similar manner.

\subsection{The Genova I Maleras Model, 1997}

Is based on the following:

1) The estimated variable is the life expectancy for women at birth, from a minimal value to a maximum value reached in a theoretical future far away from horizon year 2030.

2) The intermediate projections of the life expectancy for women are obtained by means the linearizing of logistic regression in recent years 1990, 1995, 2000, 2005 and 2010, which data are relatively current and reliable.

3) Knowing the life expectancies for the intervening years, two exemplar tables are selected in order to adjust the life expectancy for the horizon year, and thus, obtain a coefficient that is the basis to calculate the specific mortality rates by age groups.

\subsection{The Model in Women}

1) A life expectancy of 86 years [5] [6] is set, achievable in the year 2100 away from the horizon year, 2030. Until now the limits of human life have not been established in a univocal way since the medical and scientific advances make that existent proposals differ widely.

2) Life expectancies of the intermediate years of the period 2010-2030 are calculated by transforming life expectancies $e_{0}^{t}$ of the years 1990, 1995, 2000, 2005 and 2010 [7] (see second column of Table 2.2.1) using a logit function recommended by the World Bank [8],

$$
\operatorname{logit}\left(e_{0}^{t}\right)=\operatorname{Ln}\left[\frac{e_{0}^{\max }-e_{0}^{t}}{e_{0}^{t}-e_{0}^{\min }}\right]
$$

where $e_{0}^{\max }=86$ and $e_{0}^{\min }=37.5$ [6]. The logit function is widely used in social sciences and epidemiology and often is used in order to linearize models. Transformed values are shown in Table 1.

Based in this table, a linear regression model is constructed, in which the logits appear as endogenous variables $(y)$ and the years as exogenous variables $(x)$ [9]. The results of the estimation from linear regression are presented in Table 2.

\section{Table 1. Women: Logit corresponding to observed expectancies.}

\begin{tabular}{ccc}
\hline Year $\boldsymbol{X}_{\boldsymbol{i}}$ & Observed $e_{0}^{t}$ & Observed logit $\left(e_{0}^{t}\right)$ \\
\hline 1990 & 71.64 & -0.8657 \\
1995 & 74.22 & -1.1371 \\
2000 & 75.54 & -1.2908 \\
2005 & 76.65 & -1.4323 \\
2010 & 77.50 & -1.5487 \\
\hline
\end{tabular}

Source: CONAPO, INEGI and COLMEX. Demographic Conciliation, 2006 (Mimeo). CONAPO. Projections of the population in Mexico, $2005-2050$. Mexico. 
Table 2. Women: Coefficients of the regression line.

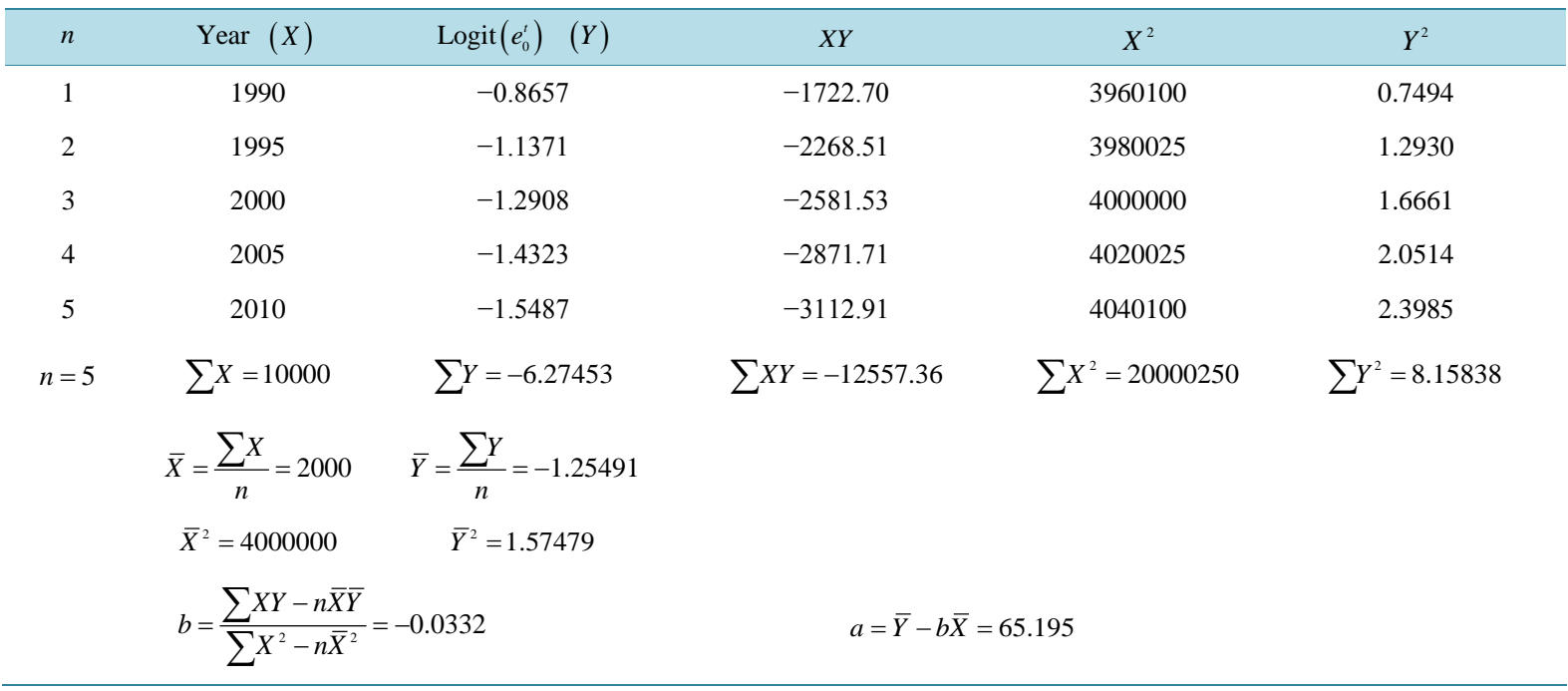

The regression line is estimated from:

$$
\hat{Y}_{i}=65.195-0.0332 \hat{X}_{i}
$$

From which the estimated logit for the years 1990-2030 (column D, Table 2.2.3) are calculated. The estimated logit for each year become in life expectancy by Equation (3) obtained from Equation (1) (column E, Table 2.2.3):

$$
e_{0}^{t}=e_{0}^{\min }+\frac{\left(e_{0}^{\max }-e_{0}^{\min }\right)}{\left[1+e^{\operatorname{logit}\left(e_{0}^{t}\right)}\right]}
$$

The final estimated series is fitted for a period of 20 years, the difference between the life expectancy of 77.50 observed in 2010 and estimated of 77.77 is 1.34 vanishing in 2030 (column F, Table 3).

3) Once it having the series of life expectancies, the mortality rates by age can be calculated for the year 2030. This is carried out by linear interpolation of the specific mortality rates of two exemplar tables, precisely those that enclose the life expectancy of horizon year, which in our case, life expectancy is 80.15 and is located between 80.00 years of exemplar Table Level 25 and 82.50 years of exemplar Table Level 26, both for UN West region with increment of 2.5 (Table 4) [4]. To find the coefficient $C^{t}$ of linear interpolation the value of $c$ is solved from the expression:

$$
(1-c) x+c y=z \text { where } 0 \leq c \leq 1
$$

The calculated rates for the year 2030 are shown in the Table 2.2.4, the mortality rates of the starting year 2010 are also included [10] [11].

\subsection{Developing the Abbreviated Mortality Table, by Sex and Age}

The last stage of the projection involves completing the remaining elements that compose a mortality table. The abbreviated table for women's mortality is presented in Table 5.

\subsection{Behavior of Mortality Tables for Women}

In Figure 1 the female mortality rate is showed, which is calculated from life expectancy with a maximum of 82 years and a minimum of 37 years, these values were set from published data by INEGI [7]. As can be observed, all age groups show for 2010 higher mortality rates and is expected to decrease gradually during the period 2010-2030. Within the primarily age groups the greatest declines can be observed, otherwise the latest groups that record the smallest decline. The expected decrease in mortality may be result of the enhancement in preventive 
Table 3. Women: logit and estimated expectancies 1990-2110.

\begin{tabular}{cccccc}
\hline $\mathbf{A}$ & $\mathbf{B}$ & $\mathbf{C}$ & $\mathbf{D}$ & $\mathbf{E}$ & $\mathbf{F}$ \\
\hline & $e_{0}^{t}$ & logit $\left(e_{0}^{t}\right)$ & logit $\left(e_{0}^{t}\right)$ & $e_{0}^{t}$ & $e_{0}^{t}$ \\
\cline { 2 - 5 } Year & Observed & Observed & Estimated & Intial Estimated & Final Estimated \\
\hline 1990 & 71.64 & -0.8657 & -0.9227 & 72.21 & 71.64 \\
1995 & 74.22 & -1.1371 & -1.0888 & 73.79 & 74.22 \\
2000 & 75.54 & -1.2908 & -1.2549 & 75.24 & 75.54 \\
2005 & 76.65 & -1.4323 & -1.4210 & 76.57 & 76.65 \\
2010 & 77.50 & -1.5487 & -1.5872 & 77.77 & 78.64 \\
2015 & & & -1.7533 & 78.84 & 79.66 \\
2020 & & & -1.9194 & 79.80 & 80.57 \\
2025 & & & -2.0855 & 80.64 & 82.38 \\
2030 & & & -2.2517 & 81.38 & 82.60 \\
2035 & & & -2.4178 & 82.03 & 83.09 \\
2040 & & & -2.5839 & 82.60 & 83.51 \\
2045 & & & -2.7500 & 83.09 & 83.87 \\
2050 & & & -2.9162 & 83.51 & 84.19 \\
2055 & & -3.0823 & 83.87 & 84.46 \\
2060 & & -3.2484 & 84.19 & 84.69 \\
2065 & & -3.4145 & 84.46 & 84.88 \\
2070 & & & -3.5807 & 84.69 & 85.05 \\
2075 & & -3.7468 & 84.88 & 85.19 \\
2080 & & -3.9129 & 85.05 & 85.31 \\
2085 & & -4.0790 & 85.19 & 85.42 \\
2090 & & -4.2452 & 85.31 & 85.42 \\
\hline
\end{tabular}

Table 4. Women: Mortality rates estimated by age group in the year 2030 and mortality rates of year 2010.

\begin{tabular}{|c|c|c|c|c|}
\hline \multirow[b]{2}{*}{ Age (Years) } & \multicolumn{2}{|c|}{ Exemplar Tables } & \multirow{3}{*}{ Year 2030 Table } & \multirow{3}{*}{ Year 2010 Table } \\
\hline & Level 25 & Level 26 & & \\
\hline & ${ }_{n} m_{x}$ & ${ }_{n} \boldsymbol{m}_{x}$ & & \\
\hline Less than 1 & 0.01014 & 0.00781 & 0.00885 & 0.01044 \\
\hline $1-4$ & 0.00050 & 0.00039 & 0.00044 & 0.00062 \\
\hline $5-9$ & 0.00019 & 0.00015 & 0.00017 & 0.00022 \\
\hline $10-14$ & 0.00016 & 0.00012 & 0.00013 & 0.00025 \\
\hline $15-19$ & 0.00026 & 0.00019 & 0.00022 & 0.00059 \\
\hline $20-24$ & 0.00037 & 0.00028 & 0.00032 & 0.00043 \\
\hline $25-29$ & 0.00045 & 0.00034 & 0.00039 & 0.00056 \\
\hline $30-34$ & 0.00056 & 0.00042 & 0.00048 & 0.00086 \\
\hline $35-39$ & 0.00075 & 0.00056 & 0.00064 & 0.00086 \\
\hline $40-44$ & 0.00109 & 0.00081 & 0.00094 & 0.00145 \\
\hline $45-49$ & 0.00174 & 0.00129 & 0.00149 & 0.00266 \\
\hline $50-54$ & 0.00267 & 0.00198 & 0.00229 & 0.00370 \\
\hline $55-59$ & 0.00420 & 0.00311 & 0.00360 & 0.00578 \\
\hline $60-64$ & 0.00678 & 0.00501 & 0.00580 & 0.01040 \\
\hline $65-69$ & 0.01231 & 0.00929 & 0.01064 & 0.01431 \\
\hline $70-74$ & 0.02249 & 0.01733 & 0.01964 & 0.02132 \\
\hline $75-79$ & 0.04093 & 0.03220 & 0.03610 & 0.03642 \\
\hline $80-84$ & 0.07444 & 0.05980 & 0.06634 & 0.06071 \\
\hline 85 and more & 0.12804 & 0.10509 & 0.11535 & 0.12125 \\
\hline$e_{t}^{0}$ & 80.0 & 82.5 & 81.38 & 77.50 \\
\hline
\end{tabular}


Table 5. Women: Mortality table projected for year 2030.

\begin{tabular}{ccccccc}
\hline Age (Years) & $\boldsymbol{n}$ & ${ }_{n} \boldsymbol{m}_{\boldsymbol{x}}$ & ${ }_{n} \boldsymbol{q}_{\boldsymbol{x}}$ & $\boldsymbol{I}_{\boldsymbol{x}}$ & ${ }_{n} \boldsymbol{L}_{\boldsymbol{x}}$ & ${ }_{n} \boldsymbol{Z}_{\boldsymbol{x}}$ \\
\hline Less than 1 & 1 & 0.00885 & 0.00881 & 100,000 & 99,560 & 0.99138 \\
$1-4$ & 4 & 0.00044 & 0.00175 & 99,119 & 396,129 & 0.99764 \\
$5-9$ & 5 & 0.00017 & 0.00084 & 98,945 & 494,518 & 0.99924 \\
$10-14$ & 5 & 0.00013 & 0.00067 & 98,862 & 494,143 & 0.99911 \\
$15-19$ & 5 & 0.00022 & 0.00111 & 98,795 & 493,704 & 0.99865 \\
$20-24$ & 5 & 0.00032 & 0.00158 & 98,686 & 493,039 & 0.99824 \\
$25-29$ & 5 & 0.00039 & 0.00194 & 98,530 & 492,171 & 0.99783 \\
$30-34$ & 5 & 0.00048 & 0.00240 & 98,339 & 491,104 & 0.99719 \\
$35-39$ & 5 & 0.00064 & 0.00322 & 98,103 & 489,725 & 0.99606 \\
$40-44$ & 5 & 0.00094 & 0.00467 & 97,787 & 487,794 & 0.99396 \\
$45-49$ & 5 & 0.00149 & 0.00742 & 97,330 & 484,845 & 0.99060 \\
$50-54$ & 5 & 0.00229 & 0.01139 & 96,608 & 480,289 & 0.98541 \\
$55-59$ & 5 & 0.00360 & 0.01783 & 95,508 & 473,281 & 0.97684 \\
$60-64$ & 5 & 0.00580 & 0.02858 & 93,805 & 462,321 & 0.95996 \\
$65-69$ & 5 & 0.01064 & 0.05183 & 91,124 & 443,811 & 0.92785 \\
$70-74$ & 5 & 0.01964 & 0.09358 & 86,401 & 411,790 & 0.87219 \\
$75-79$ & 5 & 0.03610 & 0.16557 & 78,315 & 359,160 & 0.78032 \\
$80-84$ & 5 & 0.06634 & 0.28453 & 65,349 & 280,260 & 0.08341 \\
85 and more & -- & 0.11535 & 1 & 46,755 & 23,378 & 0.07699 \\
\hline & & & & & \\
\hline
\end{tabular}

\section{Women mortality}

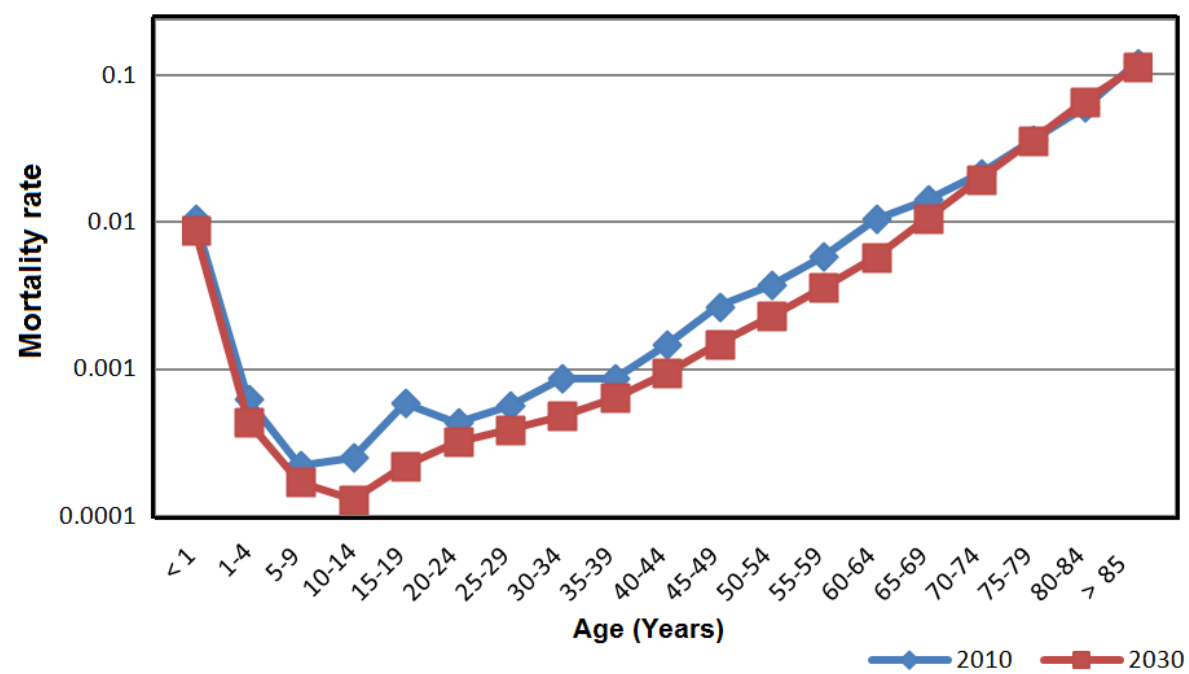

Figure 1. Mortality graph by age groups for years 2010 and 2030.

medicine and health programs that offer a wide coverage in medical services.

\section{Conclusions}

Results from projections of mortality for women population in the Hidalgo state during the period 2010-2030, 
there is a trend of reduction in mortality in the year 2030 compared to 2010, if the life expectancies behave accordingly the estimated data in this work. However, there are social, economic and health factors that could affect these indices.

The realized study predicts that during the early years of life the mortality rate of the 2030 cohort remains high compared with other age groups for the same year. During 2030 no significant changes are observed to reduce the mortality rate compared to year 2010 for age groups over 70 years.

\section{References}

[1] CEPAL/UNFPA (Economic Commission for Latin America and the Caribbean/United Nations Population Fund) (2005) Population Dynamics and Development in Latin America and the Caribbean, Population and Development Series No. 58 (LC/L.2235-P), United Nations Publication. Sales No. S.04.II.G.155, Santiago.

[2] UN United Nations (1986) Manual X: Indirect Techniques for Demographic Estimation. United Nations Publication, Sales No. S.83.XIll.2.

[3] Vinuesa, J., Zamora, F., Génova, R., Serrano, P. and Recaño, J. (1997) Demography: Analysis and Projections. Synthesis Ed. Spain.

[4] CELADE (Latin American Demographic Center) (2004) Latin America: Life Tables 1950-2025. United Nations Publication. Sales No. E/S.04.II.G.94. Santiago.

[5] CONAPO (National Population Council) (2005) Major Causes of Death in the Life Course Stages 1980-2002. Technical Paper Series CONAPO, Mexico, D.F.

[6] CONAPO (National Population Council) (2008) Projections of the Population of Mexico, Federations Entities, Municipalities and Localities 2005-2050. Methodological Document CONAPO, Mexico, D.F.

[7] INEGI (National Institute of Statistics and Geography) (2009) Historical Statistics of Mexico 2009. INEGI, México.

[8] Bulatao, R.A., et al. (1989) Projecting Mortality for All Countries. Working Paper N 337, World Bank, Washington.

[9] Montgomery, D., Peck, E. and Vining, G. (2002) Introduction to Linear Regression Analysis. Grupo Patria Cultural Ed., Mexico.

[10] INEGI (National Institute of Statistics and Geography) (2011) Statistical Yearbook of Hidalgo 2011. Hidalgo State Government INEGI, Mexico.

[11] INEGI (National Institute of Statistics and Geography) (2011) Main Results of the Population and Housing Census 2010, Hidalgo. INEGI, Mexico. 